\title{
Influence of Omeprazole and Famotidine on the Antiplatelet Effects of Clopidogrel in Addition to Aspirin in Patients With Acute Coronary Syndromes
}

\author{
- A Prospective, Randomized, Multicenter Study -
}

\author{
Hideto Yano, MD; Kengo Tsukahara, MD; Satoshi Morita, PhD; Tsutomu Endo, MD; \\ Teruyasu Sugano, MD; Kiyoshi Hibi, MD; Hideo Himeno, MD; Kazuki Fukui, MD; \\ Satoshi Umemura, MD; Kazuo Kimura, MD
}

\begin{abstract}
Background: It remains unclear whether concomitant use of omeprazole attenuates platelet function as compared with that of famotidine in patients with acute coronary syndromes (ACS) who receive clopidogrel.

Methods and Results: In this prospective study, 130 ACS patients treated with aspirin and clopidogrel who underwent stent implantation were randomly assigned to receive a Japanese standard dose of omeprazole $10 \mathrm{mg}$ daily or famotidine $20 \mathrm{mg}$ daily for at least 4 weeks. Between 14 and 28 days after enrollment, there was no significant difference in the platelet reactivity index (PRI) measured with vasodilator-stimulated phosphoprotein phosphorylation assay between the omeprazole group $(n=65)$ and famotidine group ( $n=65)(55 \pm 17 \%$ vs. $51 \pm 19 \%$; $P=0.26)$. The cumulative rate of adverse cardiovascular events at 12 months was similar in the groups (13\% vs. $17 \% ; P=0.81)$. The PRI was similar ( $54.9 \pm 17.9 \%$ vs. $54.0 \pm 17.8 \%$; $P=0.83)$ in the omeprazole group $(n=33)$ and the famotidine group $(\mathrm{n}=39)$ among patients with ST-elevation myocardial infarction (STEMI). However, there was a trend toward a higher $\mathrm{PRI}(55.2 \pm 15.9 \%$ vs. $46.4 \pm 19.4 \% ; \mathrm{P}=0.06)$ in the omeprazole group $(n=32)$ as compared with the famotidine group ( $\mathrm{n}=26)$ among patients without persistent ST-segment elevation ACS.
\end{abstract}

Conclusions: As compared with famotidine, concomitant use of low-dose omeprazole does not significantly attenuate the antiplatelet effects of clopidogrel in patients with ACS, especially in those with STEMI. (Circ J 2012; 76: 2673-2680)

Key Words: Acute coronary syndrome; Antiplatelet therapy; Clopidogrel; Platelets; Stents

$\mathbf{T}$ he benefits of dual-antiplatelet therapy (DAPT) with aspirin and clopidogrel have been established in patients with acute coronary syndromes (ACS), including those who undergo percutaneous coronary intervention (PCI). ${ }^{1-3}$ However, large clinical trials have recently demonstrated that DAPT is the most powerful predictor of gastrointestinal (GI) bleeding, which is independently associated with higher mortality in patients with ACS. ${ }^{4,5}$ Proton pump inhibitors (PPI) in combination with DAPT have thus been recommended in patients with multiple risk factors for GI bleeding. ${ }^{6}$

\section{Editorial p 2542}

Clopidogrel is a prodrug that must be metabolized by a 2-step, cytochrome P (CYP) 450-dependent process (with CYP3A4/5 and CYP2C19 playing the most important roles) to generate its active metabolite and acquire antiplatelet properties. ${ }^{7}$ Several studies have shown a broad variability in biologic response to clopidogrel, and patients with high ontreatment platelet reactivity (HTPR) who undergo PCI are at increased risk for death, myocardial infarction, and stent throm-

Received April 17, 2012; revised manuscript received May 31, 2012; accepted June 27, 2012; released online July 21, 2012 Time for primary review: 20 days

Division of Cardiology, Fujisawa City Hospital, Fujisawa (H.Y., H.H.); Division of Cardiology, Yokohama City University Medical Center, Yokohama (K.T., K.H., K.K.); Department of Biostatistics and Epidemiology, Yokohama City University School of Medicine and University Medical Center, Yokohama (S.M.); Division of Cardiology, Saiseikai Yokohama City Southern Hospital, Yokohama (T.E.); Department of Medical Science and Cardiorenal Medicine, Yokohama City University School of Medicine, Yokohama (T.S., S.U.); and Division of Cardiology, Kanagawa Cardiovascular and Respiratory Disease Center, Yokohama (K.F.), Japan

UMIN trial ID: 000002939.

Mailing address: Kengo Tsukahara, MD, Division of Cardiology, Yokohama City University Medical Center, 4-57 Urafune-cho, Minamiku, Yokohama 232-0024, Japan. E-mail: k-tsuka@urahp.yokohama-cu.ac.jp

ISSN-1346-9843 doi:10.1253/circj.CJ-12-0511

All rights are reserved to the Japanese Circulation Society. For permissions, please e-mail: cj@j-circ.or.jp 


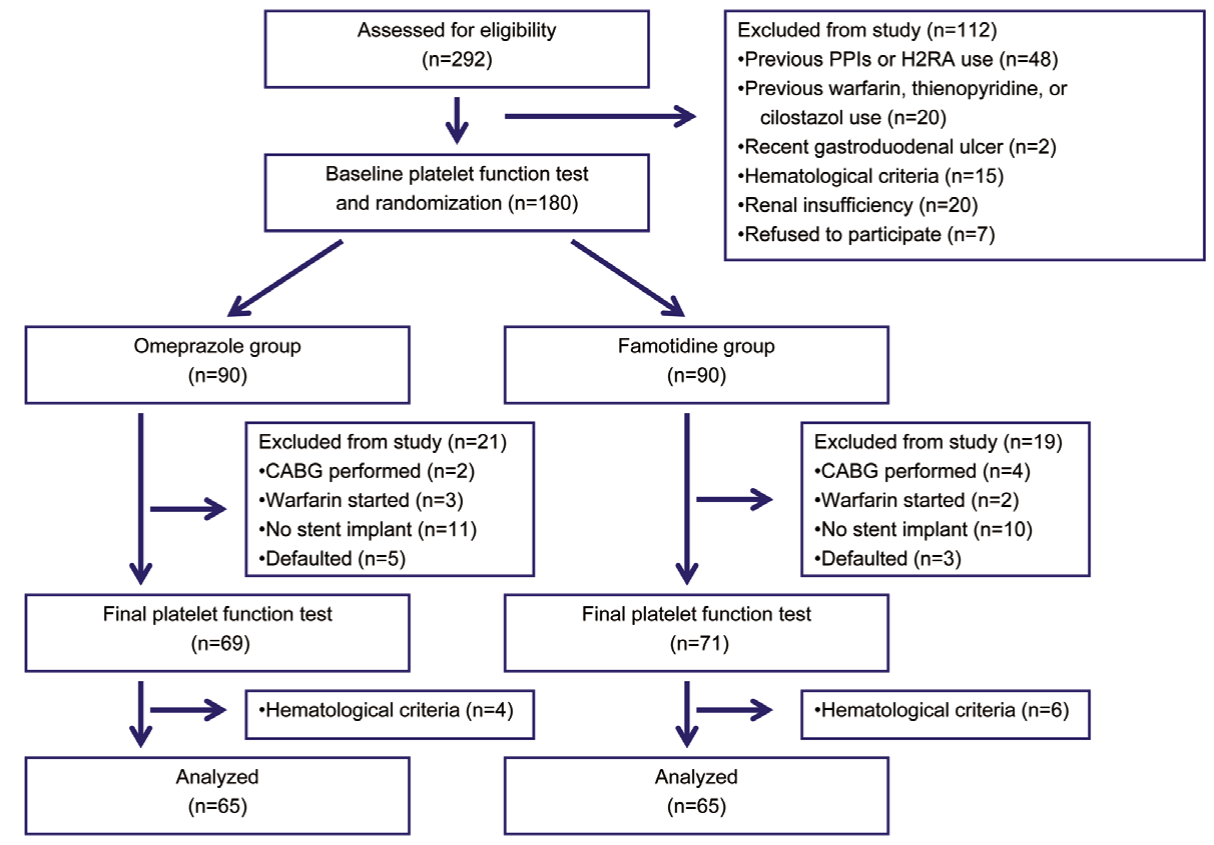

Figure 1. Flow diagram. PPI, proton pump inhibitors; H2RA, H2 receptor antagonists; CABG, coronary artery bypass grafting

bosis. ${ }^{8-10}$ Previous pharmacodynamic studies have revealed that PPI attenuate the antiplatelet effect of clopidogrel in patients with stable coronary artery disease or healthy subjects and diminish the clinical efficacy of clopidogrel in patients with coronary artery disease, including ACS. ${ }^{11,12}$ However, recent studies have shown no increase in the risk of cardiovascular events in patients treated with clopidogrel plus PPI. ${ }^{13-16}$ To our knowledge, no study has prospectively examined whether concomitant use of omeprazole attenuates the antiplatelet effects of clopidogrel in patients with ACS including ST-segment elevation myocardial infarction (STEMI).

Strategies using $\mathrm{H} 2$ receptor antagonists (H2RA) such as famotidine might be a reasonable alternative to PPI, because the effect of famotidine is independent of CYP2C19 genotype. ${ }^{17}$ To date, the impact of gastric acid-suppressing strategies (PPI vs. H2RA) on HTPR rates remains unclear. The aim of this randomized study is to assess the impacts of omeprazole and famotidine on the antiplatelet effects of clopidogrel plus aspirin in Japanese patients with ACS who undergo PCI.

\section{Methods}

We conducted a prospective, open-label, randomized, multicenter study and enrolled patients with ACS who were scheduled for coronary stent implantation and received aspirin and clopidogrel. Patients with STEMI undergoing primary PCI had to have ischemic symptoms lasting $20 \mathrm{~min}$ or more, and STsegment elevation of $\geq 1 \mathrm{~mm}$ in $\geq 2$ continuous precordial leads or in $\geq 2$ limb leads within $12 \mathrm{~h}$ after symptom onset. The inclusion criteria for ACS patients without persistent ST-segment elevation were ischemic symptoms that occurred within $72 \mathrm{~h}$ before study entry and lasted for $\geq 10 \mathrm{~min}$, and either STsegment depression of $\geq 1 \mathrm{~mm}$ or elevated levels of a cardiac biomarker of necrosis.

Exclusion criteria included major bleeding events within 7 days before enrollment, a recent history of gastric or duodenal ulcer, a serum hemoglobin level of $<10 \mathrm{~g} / \mathrm{dl}$ or $>18 \mathrm{~g} / \mathrm{dl}$, a platelet count of $<100,000 / \mathrm{mm}^{3}$ or $>500,000 / \mathrm{mm}^{3}$, hematologic or malignant disease, a serum creatinine level of $>2.0 \mathrm{mg} / \mathrm{dl}$, severe liver dysfunction, or the use of any PPI, H2RA, warfarin, thienopyridine derivative, cilostazole, glycoprotein IIb/IIIa inhibitor, or fibrinolytic agent within 7 days before enrollment. Patients with ACS caused by stent thrombosis or in-stent restenosis were also excluded. In addition, patients were excluded from analysis if they did not receive stent implantation within 14 days after symptom onset, underwent coronary artery bypass grafting (CABG), or received oral anticoagulant agents before final platelet function tests, performed between 14 and 28 days after clopidogrel loading. The study protocol was approved by the institutional review boards of all participating centers, and written informed consent was obtained from all patients.

According to a computer-generated randomization sequence at the central registration center, patients were assigned to receive a Japanese standard dose of omeprazole $10 \mathrm{mg}$ once daily or famotidine $20 \mathrm{mg}$ once daily for at least 4 weeks. Randomization was to occur before PCI was performed, and the study drug was to be administered as soon as possible after randomization. All patients also received aspirin $100 \mathrm{mg} /$ day and a 300-mg loading dose of clopidogrel followed by a maintenance dose of $75 \mathrm{mg} /$ day for at least 4 weeks. The study drug and DAPT were given at the same time. Baseline platelet function tests were performed before clopidogrel loading by means of vasodilator-stimulated phosphoprotein (VASP) phosphorylation analysis. Between 14 and 28 days after clopidogrel loading, the final platelet function test was performed. CYP2C19 $* 2$ and CYP2C19 *3 variant alleles were also determined. The attending physician was blinded to the results of VASP phosphorylation analysis and CYP2C19 genotype.

Whole blood samples were processed within $48 \mathrm{~h}$ after col- 


\begin{tabular}{|c|c|c|c|}
\hline & $\begin{array}{l}\text { Omeprazole group } \\
\qquad(n=65)\end{array}$ & $\begin{array}{l}\text { Famotidine group } \\
\qquad(n=65)\end{array}$ & P-value \\
\hline Age (years) & $67 \pm 11$ & $66 \pm 11$ & 0.58 \\
\hline Male gender & $77 \%$ & $81 \%$ & 0.51 \\
\hline Height (cm) & $164 \pm 9$ & $164 \pm 7$ & 0.75 \\
\hline Body weight $(\mathrm{kg})$ & $65 \pm 14$ & $64 \pm 10$ & 0.63 \\
\hline History of hypertension & $68 \%$ & $68 \%$ & 1.00 \\
\hline History of diabetes mellitus & $29 \%$ & $15 \%$ & 0.05 \\
\hline History of dyslipidemia & $60 \%$ & $62 \%$ & 0.85 \\
\hline Habitual smoker & $62 \%$ & $57 \%$ & 0.51 \\
\hline Previous myocardial infarction & $6 \%$ & $0 \%$ & - \\
\hline Prior $\mathrm{PCl}$ & $8 \%$ & $2 \%$ & 0.09 \\
\hline Prior CABG & $0 \%$ & $2 \%$ & - \\
\hline Previous gastroduodenal ulcer & $2 \%$ & $3 \%$ & 0.56 \\
\hline 3-vessel disease & $15 \%$ & $11 \%$ & 0.68 \\
\hline Vessel treated & & & 0.28 \\
\hline Left main & $3 \%$ & $0 \%$ & \\
\hline Left anterior descending & $53 \%$ & $43 \%$ & \\
\hline Left circumflex & $14 \%$ & $20 \%$ & \\
\hline Right coronary artery & $30 \%$ & $37 \%$ & \\
\hline Primary PCI for STEMI patients & $51 \%$ & $60 \%$ & 0.29 \\
\hline Planned PCl for the culprit artery & $49 \%$ & $40 \%$ & 0.29 \\
\hline Drug-eluting stent use & $37 \%$ & $20 \%$ & 0.05 \\
\hline Ejection fraction at discharge (\%) & $57 \pm 10$ & $56 \pm 10$ & 0.54 \\
\hline
\end{tabular}

Values are percentages or means \pm SD.

$\mathrm{PCl}$, percutaneous coronary intervention; CABG, coronary artery bypass grafting; STEMI, ST-segment elevation myocardial infarction.

lection for VASP phosphorylation analysis. We used a standardized flow-cytometric analysis (PLT VASP/P2Y12; BioCytex, Marseille, France), which is an adaptation of the method previously described by Schwarz et al. ${ }^{18}$ The platelet reactivity index (PRI) was calculated from the median fluorescence intensity (MFI) of samples incubated with prostaglandin E1 alone (PGE1) or PGE1 and adenosine diphosphate simultaneously (PGE1+ADP) according to the following calculation:

$\mathrm{PRI}=($ MFIPGE1 - MFIPGE1+ADP/MFIPGE1 $) \times 100$.

The rates of clopidogrel resistance as defined by a PRI of $\geq 50 \%$ on VASP analysis were determined in each treatment group as proposed previously. ${ }^{19} \mathrm{CYP} 2 \mathrm{C} 19$ genotypes were determined by Invader assay. Genotyping was done for CYP2C19*2 (rs4244285, c.681G>A) and CYP2C19*3 (rs4986893, c.636G>A) variants, because previous studies have reported that the CYP2C19*2 and CYP2C19*3 alleles are frequent, whereas the CYP2C19*17 allele is rare in Asians. ${ }^{20,21}$ Genomic DNA was extracted from whole blood using a commercially available QIAamp DNA Blood Mini kit (Qiagen, Venlo, Netherlands). Patients were classified into categories of metabolizer phenotypes with the use of established common-consensus star allele nomenclature. Thus, patients without a $* 2$ or $* 3$ allele were classified as "extensive metabolizers," those with one *2 or *3 allele were classified as "intermediate metabolizers," and those with two $* 2$ or $* 3$ alleles were classified as "poor metabolizers." Carriers of at least 1 loss-of-function allele were classified as "loss-of-function allele carriers".

PCI was performed in a standard manner. Primary PCI was performed immediately after administration of a loading dose of clopidogrel ( $300 \mathrm{mg}$, the Japanese standard dose). Planned PCI was performed 6 to $24 \mathrm{~h}$ after the loading dose of clopido- grel. The choice of vessels treated, devices used (including stent type), and adjunctive medication administered to support PCI was left to the discretion of the treating physician. At the time of the study, glycoprotein IIb/IIIa inhibitors and intravenous anticoagulants other than unfractionated heparin were not approved for use in patients with ACS or stent implants (or both) in Japan. All patients were required to receive aspirin indefinitely and clopidogrel for at least 12 months after stent implantation. Clinical, procedural, and outcome data were prospectively collected by independent research personnel unaware of the study aims and entered into a central database. Follow-up visits were conducted at our hospitals for at least 12 months. Patients who became unable or who were unwilling to come to our hospitals were contacted by telephone.

The primary endpoint was the incidence of clopidogrel resistance as defined by a PRI of $\geq 50 \%$ at 14 to 28 days of treatment in the 2 groups. The secondary endpoint was the incidence of adverse cardiovascular events at 12 months (including death from cardiovascular causes, spontaneous myocardial infarction, unstable angina, stent thrombosis, target vessel revascularization, non-target vessel revascularization, and ischemic stroke). Myocardial infarction was diagnosed according to the universal definition proposed in 2007. ${ }^{22}$ Stent thrombosis was classified as definite or probable according to the Academic Research Consortium definitions. ${ }^{23}$ Similar to REPLACE-2 trial, ${ }^{24}$ non-CABG related major bleeding was defined as: symptomatic intracranial, intraocular, or retroperitoneal hemorrhage, clinically overt blood loss including GI bleeding resulting in a decrease in hemoglobin by $>3 \mathrm{~g} / \mathrm{dl}$, or bleeding requiring transfusion of $\geq 2$ units of red blood cells. To assess the impact of gastric acid-suppressing strategies on protective effect of upper GI damage, we also analyzed the incidence of 


\begin{tabular}{|c|c|c|c|}
\hline & $\begin{array}{l}\text { Omeprazole group } \\
\qquad(n=65)\end{array}$ & $\begin{array}{l}\text { Famotidine group } \\
\qquad(n=65)\end{array}$ & P-value \\
\hline CYP2C19 phenotype & & & 0.26 \\
\hline EM & $29 \%$ & $17 \%$ & \\
\hline IM & $60 \%$ & $66 \%$ & \\
\hline PM & $11 \%$ & $17 \%$ & \\
\hline \multicolumn{4}{|l|}{ Blood examination at $14-28$ days } \\
\hline Leukocytes & $6,275 \pm 1,348$ & $6,194 \pm 1,574$ & 0.76 \\
\hline Hemoglobin & $13.4 \pm 1.5$ & $13.0 \pm 1.5$ & 0.12 \\
\hline Platelet count $\left(\times 10^{4}\right)$ & $25.7 \pm 5.2$ & $22.9 \pm 6.9$ & 0.01 \\
\hline Renal insufficiency* & $23 \%$ & $38 \%$ & 0.05 \\
\hline Aspirin use on admission & $11 \%$ & $14 \%$ & 0.59 \\
\hline \multicolumn{4}{|l|}{ Medications at $14-28$ days } \\
\hline Aspirin & $100 \%$ & $100 \%$ & 1.00 \\
\hline Clopidogrel & $100 \%$ & $100 \%$ & 1.00 \\
\hline Calcium channel blockers & $25 \%$ & $17 \%$ & 0.28 \\
\hline$\beta$-blockers & $55 \%$ & $52 \%$ & 0.72 \\
\hline ACE inhibitors & $45 \%$ & $51 \%$ & 0.48 \\
\hline Angiotensin II receptor blockers & $28 \%$ & $22 \%$ & 0.41 \\
\hline Statins & $89 \%$ & $83 \%$ & 0.30 \\
\hline CYP3A4 metabolized statins & $35 \%$ & $28 \%$ & 0.34 \\
\hline
\end{tabular}

Values are percentages or means \pm SD.

CYP, cytochrome; EM, extensive metabolizers; IM, intermediate metabolizers; PM, poor metabolizers.

${ }^{*}$ Renal insufficiency was defined as estimated glomerular filtration rate $<60\left(\mathrm{ml} \cdot \mathrm{min}^{-1} \cdot 1.73 \mathrm{~m}^{-2}\right)$.

\begin{tabular}{|lccc|}
\hline Table 3. Platelet Function Measurements and Clinical Outcomes & & \\
& $\begin{array}{c}\text { Omeprazole group } \\
(\mathbf{n = 6 5 )}\end{array}$ & $\begin{array}{c}\text { Famotidine group } \\
\mathbf{( n = 6 5 )}\end{array}$ & P-value \\
Vasodilator-stimulated phosphoprotein assay & & & 0.38 \\
PRI at baseline (\%) & $82.3 \pm 7.0$ & $80.9 \pm 9.3$ & 0.26 \\
PRI at 14-28 days (\%) & $55.1 \pm 16.9$ & $51.0 \pm 18.7$ & 0.38 \\
PRI $\geq 50 \%(\%)$ & $61.50 \%$ & $53.80 \%$ & 0.52 \\
Mean PRI variation (\%) & $-32.1 \pm 20.2$ & $-35.3 \pm 33.3$ & 0.68 \\
Duration of clopidogrel therapy before final platelet & $19.3 \pm 4.3$ & $19.7 \pm 4.5$ & 0.85 \\
function test (days) & & & 0.30 \\
Adverse cardiovascular events (\%) & $13 \%$ & $17 \%$ & 0.24 \\
Non-CABG-related bleeding (\%) & $5 \%$ & $2 \%$ & $3 \%$ \\
Symptoms of upper gastrointestinal damage (\%) & $0 \%$ & & \\
\hline
\end{tabular}

$\mathrm{PRI}$, platelet reactivity index; CABG, coronary artery bypass graft.

symptoms of upper GI events, such as epigastric pain, heartburn, nausea, vomiting, hematemesis, or tarry stool, confirmed by endoscopic examination with obvious findings of gastroduodenal ulcer or erosion as well as bleeding. The study was designed and conducted by the authors. The sponsor had no role in the design or conduct of the study, in the analysis of the results, or in the decision to publish the results.

Categorical variables were compared by the chi-square test and were reported as percentages. Continuous variables were compared by Student's t-test and are reported as means \pm SD. Potential predictors with $\mathrm{P}$-values of $<0.10$ on univariate analysis were included in multivariate logistic regression analysis. Odds ratios (OR) and 95\% confidence intervals (CI) were calculated. Event-free rates from the time of randomization were estimated by the Kaplan-Meier method and compared with the use of the log-rank test. P-values of $<0.05$ were considered to indicate statistical significance. Data were analyzed with SAS version 9.2 (SAS Institute Inc, Cary, NC, USA).
The required number of treated patients was estimated on the basis of a previous pharmacodynamic study. ${ }^{25}$ We estimated that a study sample size of 130 would enable an 8 percentagepoint difference in PRI to be detected, with a standard deviation of 16, an $80 \%$ statistical power, and a 5\% 2-tailed significance level. To ensure that this sample size would be available for analysis, 50 extra patients were randomized and included.

\section{Results}

Between December 2009 and March 2011, a total of 292 consecutive patients with ACS who were scheduled to undergo coronary stent implantation were assessed for eligibility. After excluding 112 patients who met the exclusion criteria, 180 were randomly assigned to treatment. Ninety patients were assigned to the omeprazole group and 90 to the famotidine group. Data on 50 patients were not analyzed: 6 underwent CABG, 5 started to receive oral anticoagulant therapy, $21 \mathrm{did}$ 


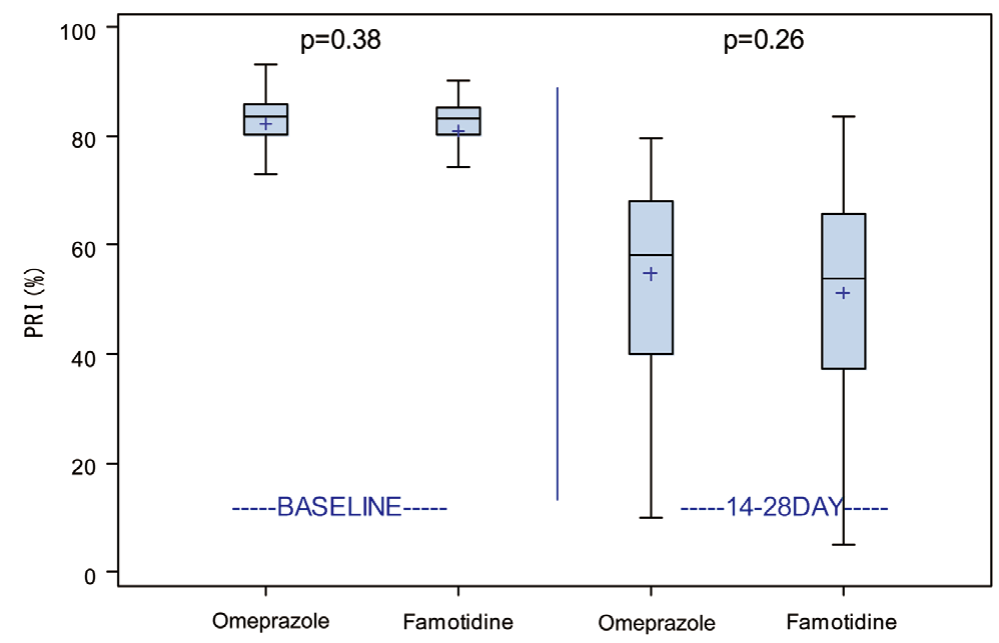

Figure 2. Mean PRI at baseline and at 14 to 28 days in the 2 groups. PRI, platelet reactivity index.

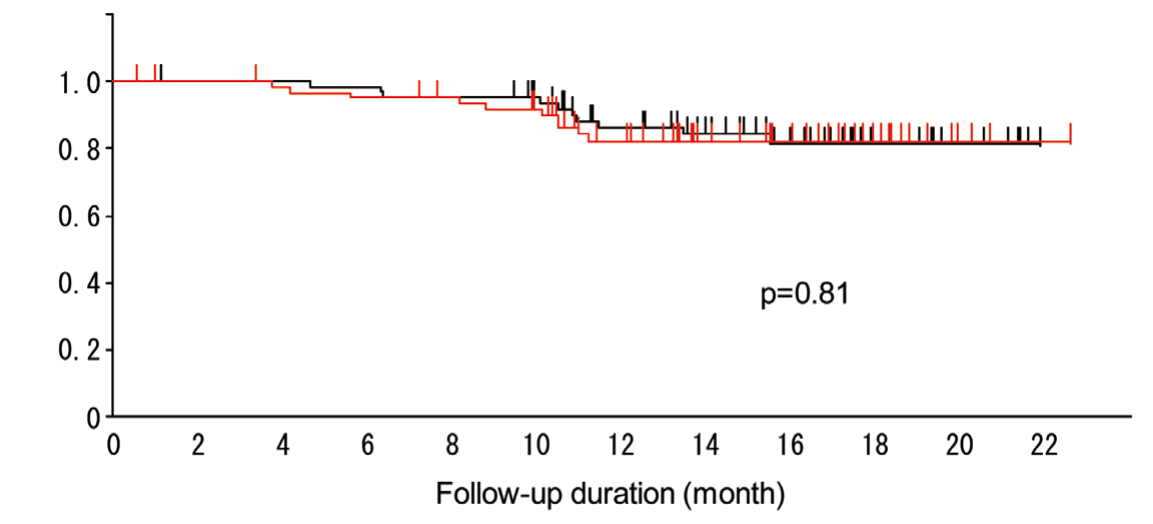

$\begin{array}{ccccccccccccc}\text { No. at risk } & & & & & & & & & & & \\ \text { Omeprazole } & 64 & 63 & 63 & 62 & 60 & 56 & 45 & 37 & 27 & 13 & 7 & 0 \\ \text { Famotidine } & 65 & 63 & 61 & 59 & 57 & 53 & 39 & 27 & 20 & 11 & 3 & 1\end{array}$

Figure 3. Kaplan-Meier curve of freedom from adverse cardiovascular events including death from cardiovascular causes, spontaneous myocardial infarction, unstable angina, stent thrombosis, any revascularization, and ischemic stroke according to group.

not undergo stent implantation within 14 days, final blood samples were not obtained from 8 patients, and 10 patients were excluded because of serum hemoglobin levels or platelet counts meeting the exclusion criteria at final platelet function testing. The final analysis thus included data on 130 patients: 65 patients in the omeprazole group and 65 in the famotidine group. Among these patients, 72 had STEMI and 58 had ACS without persistent ST-segment elevation. A flowchart of the patients is shown in Figure 1. There was no significant difference in the baseline characteristics between 130 patients and 50 patients who were not excluded (data not shown).

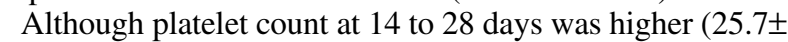
5.2 vs. $22.9 \pm 6.9 ; \mathrm{P}=0.01)$, and the incidence of diabetes mellitus $(29 \%$ vs. $15 \% ; \mathrm{P}=0.05)$ and drug-eluting stent use $(37 \%$ vs. $20 \% ; \mathrm{P}=0.05$ ) tended to be higher in the omeprazole group than in the famotidine group, there were no clinically significant differences in age, sex, or the incidence of other coronary risk factors between the 2 treatment groups. More than half of patients had CYP2C19 loss-of-function alleles (71\% vs. $83 \%$ ) and STEMI (51\% vs. $60 \%$ ), with no significant differences between the groups (Tables 1,2). The median duration of clopidogrel therapy before final platelet function test was similar in the omeprazole and famotidine groups (19.3 \pm 4.3 days vs. $19.7 \pm 4.5$ days; $\mathrm{P}=0.68$ ) (Table 3 ). The mean PRI at baseline $(82.3 \pm 7.0 \%$ vs. $80.9 \pm 9.3 \% ; \mathrm{P}=0.38)$ was similar in the groups, and the PRI at 14 to 28 days significantly decreased from baseline in both groups and did not differ significantly between the groups (55.1 $\pm 16.9 \%$ vs. $51.0 \pm 18.7 \%$; $P=0.26$ ) (Figure 2$)$. The proportion of patients with clopidogrel resistance as defined by a PRI of $\geq 50 \%$ also did not differ (61.5\% vs. $53.8 \%$; $\mathrm{P}=0.38)$. The mean PRI variation was $-32.1 \%$ in the omeprazole group and $-35.3 \%$ in the famotidine group $(\mathrm{P}=0.52)$ (Table 3$)$. The individual data was shown in Figures S1A and S1B.

No patient was lost to follow-up. The cumulative frequency of adverse cardiovascular events at 12 months was similar in the groups ( $13 \%$ vs. $17 \%$; $\mathrm{P}=0.81$ ) (Figure 3 ). The most com- 


\begin{tabular}{|c|c|c|c|c|c|c|}
\hline & \multicolumn{3}{|c|}{ Patients with STEMI } & \multicolumn{3}{|c|}{ Patients without persistent ST elevation } \\
\hline & $\begin{array}{l}\text { Omeprazole } \\
\text { group }(n=33)\end{array}$ & $\begin{array}{l}\text { Famotidine } \\
\text { group }(n=39)\end{array}$ & P-value & $\begin{array}{l}\text { Omeprazole } \\
\text { group }(n=32)\end{array}$ & $\begin{array}{l}\text { Famotidine } \\
\text { group }(n=26)\end{array}$ & P-value \\
\hline Age (years) & $67 \pm 10$ & $64 \pm 12$ & 0.33 & $67 \pm 12$ & $69 \pm 10$ & 0.52 \\
\hline Male gender & $76 \%$ & $85 \%$ & 0.19 & $78 \%$ & $77 \%$ & 0.91 \\
\hline Height $(\mathrm{cm})$ & $164 \pm 8$ & $165 \pm 8$ & 0.37 & $164 \pm 9$ & $163 \pm 8$ & 0.65 \\
\hline Body weight (kg) & $62 \pm 12$ & $66 \pm 10$ & 0.52 & $68 \pm 16$ & $62 \pm 10$ & 0.07 \\
\hline History of hypertension & $82 \%$ & $67 \%$ & 0.14 & $53 \%$ & $69 \%$ & 0.21 \\
\hline History of diabetes mellitus & $27 \%$ & $15 \%$ & 0.21 & $31 \%$ & $15 \%$ & 0.16 \\
\hline History of dyslipidemia & $49 \%$ & $69 \%$ & 0.07 & $72 \%$ & $50 \%$ & 0.08 \\
\hline Habitual smoker & $70 \%$ & $54 \%$ & 0.16 & $53 \%$ & $62 \%$ & 0.52 \\
\hline Previous myocardial infarction & $0 \%$ & $0 \%$ & - & $13 \%$ & $0 \%$ & - \\
\hline Prior PCl & $0 \%$ & $3 \%$ & - & $16 \%$ & $0 \%$ & - \\
\hline Prior CABG & $0 \%$ & $0 \%$ & - & $0 \%$ & $0 \%$ & - \\
\hline Previous gastroduodenal ulcer & $0 \%$ & $3 \%$ & - & $3 \%$ & $4 \%$ & 0.88 \\
\hline Renal insufficiency ${ }^{*}$ & $18 \%$ & $44 \%$ & 0.02 & $28 \%$ & $31 \%$ & 0.82 \\
\hline 3-vessel disease & $9 \%$ & $15 \%$ & 0.72 & $22 \%$ & $4 \%$ & 0.11 \\
\hline Drug-eluting stent use & $9 \%$ & $0 \%$ & 0.17 & $66 \%$ & $50 \%$ & 0.17 \\
\hline Ejection fraction at discharge (\%) & $57 \pm 11$ & $53 \pm 11$ & 0.19 & $58 \pm 9$ & $60 \pm 8$ & 0.27 \\
\hline CYP2C19 phenotype & & & 0.28 & & & 0.79 \\
\hline EM & $32 \%$ & $17 \%$ & & $25 \%$ & $17 \%$ & \\
\hline IM & $57 \%$ & $64 \%$ & & $64 \%$ & $70 \%$ & \\
\hline PM & $11 \%$ & $19 \%$ & & $11 \%$ & $13 \%$ & \\
\hline \multicolumn{7}{|l|}{$\begin{array}{l}\text { Vasodilator-stimulated phosphopro- } \\
\text { tein assay }\end{array}$} \\
\hline PRI at baseline (\%) & $81.9 \pm 8.7$ & $80.3 \pm 11.5$ & 0.53 & $82.8 \pm 4.7$ & $81.8 \pm 4.4$ & 0.42 \\
\hline PRI at $14-28$ days $(\%)$ & $54.9 \pm 17.9$ & $54.0 \pm 17.8$ & 0.83 & $55.2 \pm 15.9$ & $46.4 \pm 19.4$ & 0.06 \\
\hline $\mathrm{PRI} \geq 50 \%(\%)$ & $58 \%$ & $59 \%$ & 0.90 & $66 \%$ & $46 \%$ & 0.13 \\
\hline Mean PRI variation (\%) & $-32.1 \pm 21.8$ & $-29.2 \pm 37.8$ & 0.70 & $-32.1 \pm 18.9$ & $-44.6 \pm 22.7$ & 0.03 \\
\hline
\end{tabular}

Values are percentages or means \pm SD.

ACS, acute coronary syndromes. Other abbreviations as in Tables 1-3.

Renal insufficiency was defined as estimated glomerular filtration rate $<60\left(\mathrm{ml} \cdot \mathrm{min}^{-1} \cdot 1.73 \mathrm{~m}^{-2}\right)$.

\begin{tabular}{|lcc|}
\hline \multicolumn{3}{|c|}{ Table 5. Predictors of PRI $\geq \mathbf{5 0 \%}$ at $\mathbf{1 4}$ to $\mathbf{2 8}$ Days } \\
OR (95\% Cl) & P-value \\
IM or PM & $3.59(1.21-10.60)$ & 0.02 \\
Calcium channel blockers use & $2.87(0.84-9.79)$ & 0.09 \\
Obesity $^{*}$ & $2.12(0.76-5.92)$ & 0.15 \\
\hline
\end{tabular}

$\mathrm{OR}$, odds ratio; $\mathrm{Cl}$, confidence interval. Other abbreviations as in Tables 2,3.

Potential predictors, which were demographic, clinical, and angiographic variables with P-values of $<0.10$ on univariate analysis, were included in a multivariate logistic regression analysis.

${ }^{*}$ Obesity was defined as body mass index $>25\left(\mathrm{~kg} / \mathrm{m}^{2}\right)$.

mon adverse events were target vessel revascularization and non-target vessel revascularization. Only 1 patient had ischemic stroke; however, there was no death from cardiovascular causes, myocardial infarction, or stent thrombosis during follow-up. Three patients had non-CABG-related, major colonic bleeding in the omeprazole group, and 1 patient had major bleeding from a gastric ulcer in the famotidine group. Only 2 patients in the famotidine group had symptoms of upper GI damage (including upper GI bleeding in 1 patient) (Table 3).

As a post-hoc analysis, we compared the impact of gastric acid-suppressing agents on the antiplatelet effects of clopidogrel in patients with STEMI $(n=72)$ and those without persistent ST-segment elevation ACS $(n=58)$. Among patients with
STEMI, there were no significant differences between the omeprazole group $(n=33)$ and the famotidine group $(n=39)$ in baseline characteristics other than the rate of renal insufficiency ( $18 \%$ vs. $44 \% ; \mathrm{P}=0.02)$. The mean PRI at baseline $(81.9 \pm 8.7 \%$ vs. $80.3 \pm 11.5 \% ; \mathrm{P}=0.53)$ and at 14 to 28 days $(54.9 \pm 17.9 \%$ vs. $54.0 \pm 17.8 \%$; $\mathrm{P}=0.83)$ were similar in the treatment groups (Table 4). Among patients without persistent STsegment elevation ACS, there were no significant differences in patient characteristics other than platelet count at 14 to 28 days $\left(20.6 \pm 6.1\left(\times 10^{4}\right)\right.$ vs. $\left.24.2 \pm 4.9\left(\times 10^{4}\right) ; \mathrm{P}=0.02\right)$ between the omeprazole group $(n=32)$ and the famotidine group $(n=26)$. Although the baseline PRI was similar in the treatment groups ( $82.8 \pm 4.7 \%$ vs. $81.8 \pm 4.4 \% ; \mathrm{P}=0.42)$, there were trends toward a higher PRI at 14 to 28 days $(55.2 \pm 15.9 \%$ vs. $46.4 \pm 19.4 \%$; $\mathrm{P}=0.06)$ and a higher rate of clopidogrel resistance as defined by a PRI of $\geq 50 \%$ ( $65.6 \%$ vs. $46.2 \%$; $\mathrm{P}=0.13)$ in the omeprazole group as compared with the famotidine group. The mean PRI variation was $-32.1 \%$ in the omeprazole group as compared with $-44.6 \%$ in the famotidine group after 14 to 28 days of treatment $(\mathrm{P}=0.03)$ (Table 4). On multivariate logistic regression analysis, CYP2C19 loss-of-function allele carriage (intermediate metabolizers or poor metabolizers) was the only independent predictor of PRI $\geq 50 \%$ at 14 to 28 days (OR: 3.59 , 95\% CI: $1.21-10.60, \mathrm{P}=0.02$ ), whereas concomitant PPI use, precious PCI, diabetes mellitus, renal insufficiency, primary PCI for STEMI, and drug-eluting stent use were not (Table 5). 


\section{Discussion}

In the present randomized study, as compared with famotidine, omeprazole did not significantly decrease the antiplatelet effect of clopidogrel as evaluated by VASP phosphorylation at 14 to 28 days in patients with ACS who underwent stent implantation (primary endpoint). The cumulative rate of adverse outcomes at 12 months did not differ between the omeprazole group and famotidine group. There was no significant difference in the incidence of non-CABG related major bleeding between the groups. Only 2 patients in the famotidine group had symptoms of upper GI damage. In the comparison of the PRI at 14 to 28 days between types of ACS, there were trends toward a higher PRI and the smaller PRI variation in the omeprazole group as compared with the famotidine group among those without persistent ST-segment elevation ACS; however, they were similar in the treatment groups among patients with STEMI. Multivariate logistic regression analysis showed that at least 1 CYP2C19 loss-of-function allele carriage was the only independent predictor of clopidogrel resistance.

In contrast to the results of previous pharmacodynamic studies in patients with stable coronary disease,${ }^{25-27}$ our findings showed that the concomitant use of omeprazole did not significantly attenuate the antiplatelet effects of clopidogrel as compared with famotidine in the setting of ACS. Several reasons might account for the negative impact of clopidogrel responsiveness in patients who received omeprazole, compared with famotidine. First, a low dose of omeprazole ( $10 \mathrm{mg} /$ day) was used in the study. This dose level is usually prescribed to prevent the development of aspirin-induced gastric ulcers in Japanese patients. Second, more than half of our patients had STEMI and received primary PCI. Among patients treated with famotidine, there was a trend toward a higher PRI at 14 to 28 days in patients with STEMI than in those without persistent ST-segment elevation $(54.0 \pm 17.8 \%$ vs. $46.4 \pm 19.4 \% ; \mathrm{P}=0.12)$. This result suggests that increased platelet activation might persist beyond 14 days after primary PCI, ${ }^{28}$ potentially limiting the effectiveness of a standard dose of antiplatelet agents in patients with STEMI. Third, the incidence of CYP2C19 loss-of-function alleles was extremely high among our participants. A pharmacodynamic study has demonstrated that omeprazole decreases the antiplatelet effect of clopidogrel in noncarriers, but not in carriers of CYP2C19 loss-of-function alleles. ${ }^{29}$ In the present study, there was no significant difference in the PRI at 14 to 28 days between patients treated with omeprazole and those with famotidine among each CYP2C19 phenotype, respectively (Table S1). A larger sample size might be needed to find a significant difference in the PRI between the groups among non-carriers.

In the present study, only a few patients had symptoms of upper GI damage in the famotidine group, and no patient who received low-dose omeprazole reported such symptoms. Recent studies demonstrated that concomitant use of a PPI and clopidogrel was not associated with an increased risk of adverse outcomes with a higher frequency of GI events in Japanese patients treated with stents, ${ }^{30,31}$ although both larger studies were non-randomized and use of PPI other than omeprazole was permitted. Our results might explain the mechanism of the results of above 2 larger studies, which could provide a rationale for the concomitant use of PPI in Japanese patients who receive DAPT, particularly those at greatest risk for upper GI bleeding. The rate of major bleeding was not low (3.1\%) in the present study. The incidence of major bleeding ranged from $0.2 \%$ to $9.1 \%$ in the recent large randomized clinical trials evaluating antithrombotic drugs in ACS and PCI, because of the variation in bleeding definitions used. ${ }^{32}$ Our result seems comparable to the incidence of major bleeding (3.2\%) in the REPLACE-2 trial.

Another important issue related to HTPR is CYP2C19 polymorphisms. It is not evident why the prevalence of CYP2C19 LOF allele carriers is high in our study patients with ACS. There was no significant difference in the percentage of patients with CYP2C19 loss-of-function allele carriage between analyzed patients and 62 patients with ACS who were excluded from the study and determined CYP2C19 phenotype (77\% vs. $68 \%, \mathrm{P}=0.15$ ) (data not shown). Recent studies have reported the role of CYP epoxygenase system regulating inflammation and vascular tone, which is connected with the cardiovascular protective effects. ${ }^{33}$ Genomic substudy of the CHARISMA trial revealed that there was an increased risk for cardiovascular events among carriers of CYP2C19 polymorphisms in the placebo arm in comparison with non-carriers. These findings suggest that CYP2C19 polymorphisms itself might be conferring excess risk even in patients who do not receive clopidogrel.

Our study had several important limitations. First, clinical outcomes were evaluated in a small group of patients. Second, platelet function might not have reached a stable state 14 to 28 days after PCI in some of the participants, because all patients underwent coronary stent implantation during the acute phase of ACS. We did not perform additional platelet function tests $>28$ days after clopidogrel loading. However, the risk of stent thrombosis has been reported to be highest within 30 days after stent implantation, especially in patients with ACS who undergo emergency PCI. ${ }^{34-36}$ Third, platelet function testing was performed only by a single method with the use of VASP phosphorylation analysis. However, VASP phosphorylation analysis is the only test that specifically assesses P2Y12 receptor activity. ${ }^{19}$ Fourth, the present study was not placebo-controlled. The gastric acid-suppressing effect of H2RA might reduce intestinal absorption of clopidogrel; however, there is no inhibitory potential of famotidine on the metabolic activation of clopidogrel. ${ }^{37}$ We therefore used famotidine as a control agent. Finally, the definition of HTPR has not been established in Japanese patients. Although the proportion of patients showing HTPR was high, the incidence of thrombotic events was very low in our study. Cardiovascular events such as stent thrombosis have been reported to be less common in Asians than in Westerners. ${ }^{34,36,38}$

\section{Conclusions}

As compared with famotidine, concomitant use of low-dose omeprazole does not significantly attenuate the antiplatelet effects of clopidogrel in patients with ACS, especially in those with STEMI.

\section{Acknowledgments}

The work was supported by a grant from Daiichi Sankyo Co, Ltd.

\section{References}

1. Yusuf S, Zhao F, Mehta SR, Chrolavicius S, Tognoni G, Fox KK. Effects of clopidogrel in addition to aspirin in patients with acute coronary syndromes without ST-segment elevation. $N$ Engl J Med 2001; 345: 494-502.

2. Steinhubl SR, Berger PB, Mann JT 3rd, Fry ET, DeLago A, Wilmer C, et al. Early and sustained dual oral antiplatelet therapy following percutaneous coronary intervention: A randomized controlled trial. JAMA 2002; 288: $2411-2420$.

3. Sabatine MS, Cannon CP, Gibson CM, Lopez-Sendon JL, Montalescot $\mathrm{G}$, Theroux P, et al. Addition of clopidogrel to aspirin and fibrinolytic therapy for myocardial infarction with ST-segment elevation. $N$ Engl J Med 2005; 352: 1179-1189. 
4. Nikolsky E, Stone GW, Kirtane AJ, Dangas GD, Lansky AJ, McLaurin $\mathrm{B}$, et al. Gastrointestinal bleeding in patients with acute coronary syndromes: Incidence, predictors, and clinical implications: Analysis from the ACUITY (Acute Catheterization and Urgent Intervention Triage Strategy) trial. J Am Coll Cardiol 2009; 54: 1293-1302.

5. Moukarbel GV, Signorovitch JE, Pfeffer MA, McMurray JJ, White $\mathrm{HD}$, Maggioni AP, et al. Gastrointestinal bleeding in high risk survivors of myocardial infarction: The VALIANT Trial. Eur Heart $J$ 2009; 30: 2226-2232.

6. Hamm CW, Bassand JP, Agewall S, Bax J, Boersma E, Bueno H, et al. ESC Guidelines for the management of acute coronary syndromes in patients presenting without persistent ST-segment elevation: The Task Force for the management of acute coronary syndromes (ACS) in patients presenting without persistent ST-segment elevation of the European Society of Cardiology (ESC). Eur Heart J 2011; 32: 29993054.

7. Kazui M, Nishiya Y, Ishizuka T, Hagihara K, Farid NA, Okazaki O, et al. Identification of the human cytochrome P450 enzymes involved in the two oxidative steps in the bioactivation of clopidogrel to its pharmacologically active metabolite. Drug Metab Dispos 2010; 38: 92-99.

8. Matetzky S, Shenkman B, Guetta V, Shechter M, Bienart R, Goldenberg I, et al. Clopidogrel resistance is associated with increased risk of recurrent atherothrombotic events in patients with acute myocardial infarction. Circulation 2004; 109: 3171-3175.

9. Cuisset T, Frere C, Quilici J, Barbou F, Morange PE, Hovasse T, et al. High post-treatment platelet reactivity identified low-responders to dual antiplatelet therapy at increased risk of recurrent cardiovascular events after stenting for acute coronary syndrome. J Thromb Haemost 2006; 4: 542-549.

10. Tsukahara K, Kimura K, Morita S, Ebina T, Kosuge M, Hibi K, et al. Impact of high-responsiveness to dual antiplatelet therapy on bleeding complications in patients receiving drug-eluting stents. Circ J 2010; 74: 679-685.

11. Ho PM, Maddox TM, Wang L, Fihn SD, Jesse RL, Peterson ED, et al. Risk of adverse outcomes associated with concomitant use of clopidogrel and proton pump inhibitors following acute coronary syndrome. JAMA 2009; 301: 937-944.

12. Juurlink DN, Gomes T, Ko DT, Szmitko PE, Austin PC, Tu JV, et al. A population-based study of the drug interaction between proton pump inhibitors and clopidogrel. CMAJ 2009; 180: 713-718.

13. O'Donoghue ML, Braunwald E, Antman EM, Murphy SA, Bates ER, Rozenman Y, et al. Pharmacodynamic effect and clinical efficacy of clopidogrel and prasugrel with or without a proton-pump inhibitor: An analysis of two randomised trials. Lancet 2009; 374: 989-997.

14. Rassen JA, Choudhry NK, Avorn J, Schneeweiss S. Cardiovascular outcomes and mortality in patients using clopidogrel with proton pump inhibitors after percutaneous coronary intervention or acute coronary syndrome. Circulation 2009; 120: 2322-2329.

15. Ray WA, Murray KT, Griffin MR, Chung CP, Smalley WE, Hall K, et al. Outcomes with concurrent use of clopidogrel and proton-pump inhibitors: A cohort study. Ann Intern Med 2010; 152: 337-345.

16. Simon T, Steg PG, Gilard M, Blanchard D, Bonello L, Hanssen M, et al. Clinical events as a function of proton pump inhibitor use, clopidogrel use, and cytochrome P450 2C19 genotype in a large nationwide cohort of acute myocardial infarction: Results from the French Registry of Acute ST-Elevation and Non-ST-Elevation Myocardial Infarction (FAST-MI) registry. Circulation 2011; 123: 474-482.

17. Taha AS, McCloskey C, Prasad R, Bezlyak V. Famotidine for the prevention of peptic ulcers and oesophagitis in patients taking lowdose aspirin (FAMOUS): A phase III, randomised, double-blind, placebo-controlled trial. Lancet 2009; 374: 119-125.

18. Schwarz UR, Geiger J, Walter U, Eigenthaler M. Flow cytometry analysis of intracellular VASP phosphorylation for the assessment of activating and inhibitory signal transduction pathways in human platelets--definition and detection of ticlopidine/clopidogrel effects. Thromb Haemost 1999; 82: 1145-1152.

19. Bonello L, Tantry US, Marcucci R, Blindt R, Angiolillo DJ, Becker R, et al. Consensus and future directions on the definition of high ontreatment platelet reactivity to adenosine diphosphate. $J$ Am Coll Cardiol 2010; 56: 919-933.

20. Lee JM, Park S, Shin DJ, Choi D, Shim CY, Ko YG, et al. Relation of genetic polymorphisms in the cytochrome $\mathrm{P} 450$ gene with clopidogrel resistance after drug-eluting stent implantation in Koreans. Am J Cardiol 2009; 104: 46-51.

21. Sugimoto K, Uno T, Yamazaki H, Tateishi T. Limited frequency of the CYP2C19*17 allele and its minor role in a Japanese population. Br J Clin Pharmacol 2008; 65: 437-439.

22. Thygesen K, Alpert JS, White HD, Jaffe AS, Apple FS, Galvani M, et al. Universal definition of myocardial infarction. Circulation 2007; 116: $2634-2653$.

23. Cutlip DE, Windecker S, Mehran R, Boam A, Cohen DJ, van Es GA, et al. Clinical end points in coronary stent trials: A case for standardized definitions. Circulation 2007; 115: 2344-2351.

24. Lincoff AM, Bittl JA, Harrington RA, Feit F, Kleiman NS, Jackman $\mathrm{JD}$, et al. Bivalirudin and provisional glycoprotein IIb/IIIa blockade compared with heparin and planned glycoprotein IIb/IIIa blockade during percutaneous coronary intervention: REPLACE-2 randomized trial. JAMA 2003; 289: 853-863.

25. Gilard M, Arnaud B, Cornily JC, Le Gal G, Lacut K, Le Calvez G, et al. Influence of omeprazole on the antiplatelet action of clopidogrel associated with aspirin: The randomized, double-blind OCLA (Omeprazole CLopidogrel Aspirin) study. J Am Coll Cardiol 2008; 51: $256-260$.

26. Small DS, Farid NA, Payne CD, Weerakkody GJ, Li YG, Brandt JT, et al. Effects of the proton pump inhibitor lansoprazole on the pharmacokinetics and pharmacodynamics of prasugrel and clopidogrel. J Clin Pharmacol 2008; 48: 475-484.

27. Siriswangvat S, Sansanayudh N, Nathisuwan S, Panomvana D. Comparison between the effect of omeprazole and rabeprazole on the antiplatelet action of clopidogrel. Circ J 2010; 74: 2187-2192.

28. Tselepis AD, Tsoukatos D, Droudes C, Donas A, Evangelou A. Platelet response to the aggregatory effect of platelet activating factor (PAF) ex vivo in patients with acute myocardial infarction. Eur J Clin Invest 1991; 21: 490-496.

29. Furuta T, Iwaki T, Umemura K. Influences of different proton pump inhibitors on the anti-platelet function of clopidogrel in relation to CYP2C19 genotypes. Br J Clin Pharmacol 2010; 70: 383-392.

30. Aihara H, Sato A, Takeyasu N, Nishina H, Hoshi T, Akiyama D, et al. Effect of individual proton pump inhibitors on cardiovascular events in patients treated with clopidogrel following coronary stenting: Results from the Ibaraki Cardiac Assessment Study Registry. Catheter Cardiovasc Interv 2012 January 10 [Epub ahead of print].

31. Chitose T, Hokimoto S, Oshima S, Nakao K, Fujimoto K, Miyao Y, et al. Clinical outcomes following coronary stenting in Japanese patients treated with and without proton pump inhibitor. Circ J 2012; 76: $71-78$

32. Steinhubl SR, Kastrati A, Berger PB. Variation in the definitions of bleeding in clinical trials of patients with acute coronary syndromes and undergoing percutaneous coronary interventions and its impact on the apparent safety of antithrombotic drugs. Am Heart J 2007; 154: $3-11$

33. Deng Y, Theken KN, Lee CR. Cytochrome P450 epoxygenases, soluble epoxide hydrolase, and the regulation of cardiovascular inflammation. J Mol Cell Cardiol 2010; 48: 331 -341.

34. Daemen J, Wenaweser P, Tsuchida K, Abrecht L, Vaina S, Morger C, et al. Early and late coronary stent thrombosis of sirolimus-eluting and paclitaxel-eluting stents in routine clinical practice: Data from a large two-institutional cohort study. Lancet 2007; 369: 667-678.

35. Kimura T, Morimoto T, Nakagawa Y, Tamura T, Kadota K, Yasumoto $\mathrm{H}$, et al. Antiplatelet therapy and stent thrombosis after sirolimuseluting stent implantation. Circulation 2009; 119: 987-995.

36. Aoki J, Lansky AJ, Mehran R, Moses J, Bertrand ME, McLaurin BT, et al. Early stent thrombosis in patients with acute coronary syndromes treated with drug-eluting and bare metal stents: The Acute Catheterization and Urgent Intervention Triage Strategy trial. Circulation 2009; 119: 687-698.

37. Ohbuchi M, Noguchi K, Kawamura A, Usui T. Different effects of proton pump inhibitors and famotidine on the clopidogrel metabolic activation by recombinant CYP2B6, CYP2C19 and CYP3A4. Xenobiotica 2012; 42: 633-640.

38. Meadows TA, Bhatt DL, Cannon CP, Gersh BJ, Rother J, Goto S, et al. Ethnic differences in cardiovascular risks and mortality in atherothrombotic disease: Insights from the Reduction of Atherothrombosis for Continued Health (REACH) registry. Mayo Clin Proc 2011; 86: $960-967$.

\section{Supplementary Files}

Supplementary File 1

Figure S1. (A) Individual data of the platelet reactivity index (PRI) in the omeprazole group.

Table S1. Platelet Function Measurements Among Each CYP2C19 Phenotype

Please find supplementary file(s);

http://dx.doi.org/10.1253/circj.CJ-12-0511 